\title{
SILICATO DE CA E MG: PROPRIEDADES QUÍMICAS E FÍSICAS DO SOLO E PRODUTIVIDADE DO QUIABEIRO
}

\author{
Emmerson Rodrigues Moraes ${ }^{1}$, Israel Mendes Sousa², Joicy Vitória Miranda Peixoto³ ${ }^{3}$ Elias Nascentes \\ Borges $^{4}$, Rodrigo Vieira da Silva ${ }^{5}$
}

\begin{abstract}
RESUMO - Objetivou-se estimar os efeitos do silicato de cálcio e magnésio em horta sob produção de quiabeiro em comparação a solos com pastagem e sob "saia” do cafeeiro. Utilizou-se o delineamento em blocos ao acaso, com cinco tratamentos e dois manejos alternativos adicionais em cinco repetições. Os tratamentos consistiram em cinco doses de silicato de cálcio e magnésio: 0; 0,5; 1,0; 2,0 e 4,0 t ha-1 e os adicionais: solo sob "saia" do cafeeiro e pastagem. Os atributos físicos avaliados consistiram em: argila dispersa em água, macroporosidade, microporosidade, porosidade total, grau de floculação e diâmetro médio geométrico. Para a determinação de produtividade de plantas de quiabeiro, realizou-se a colheita de quiabo a partir dos 60 dias após o transplantio, duas vezes por semana durante 75 dias. O silicato de cálcio e magnésio não aumenta a produtividade de plantas de quiabo em solo com pH acima de 5,9. Há melhoria dos atributos físicos associados a agregação do solo (diâmetro médio agregado, grau de floculação e argila dispersa em água). O silicato de cálcio e magnésio reduz a acidez do solo e eleva os teores de silício disponíveis no solo.
\end{abstract}

Palavras-chave: agregados do solo, hortaliça, manejo do solo, nutrientes.

\section{SILICATE CA AND MG: CHEMICAL AND PHYSICAL PROPERTIES OF SOIL AND PRODUCTIVITY OF OKRA}

\begin{abstract}
This study aimed to estimate the effects of calcium and magnesium silicate in the production of okra which is on nursery comparing it to soils which are pasture and seedlings that are under the "skirt" of coffee tree. We used the randomized block design with five treatments and two additional alternative practices in five replicates. The treatments consisted of five doses of calcium silicate and magnesium: $0 ; 0.5 ; 1.0$; 2.0 to 4.0 t ha-1 and additional: soil under coffee "skirt" and pasture. The physical attributes consisted in: texture (slim sand, grit, silt and clay), clay scattered on water, macroporosity, microporosity, total porosity, degree of flocculation and mean geometric diameter. The determination of the productivity, the harvest was made since 60 days after the planting and after then, twice a week until it completes 75 days. The calcium and magnesium silicate does not increase the productivity of okra in soil which has a pH above 5.9. There is improvement in the physical attributes associated with soil aggregation (mean diameter of the aggregate, degree of flocculation and clay dispersion in the water). The calcium and magnesium silicate reduces soil acidity and elevates the levels of available silicon in the soil.
\end{abstract}

Keywords: soil aggregates, soil fertility, soil management, vegetable.

\footnotetext{
${ }^{1} 1$ Professor Mestre em Solos. Instituto Federal de Educação, Ciência e Tecnologia Goiano - Campus Morrinhos, BR-153, km 633, Zona Rural, CEP: 75.650-000, Morrinhos, GO, Brasil. emmerson.moraes@ifgoiano.edu.br

${ }^{2}$ Mestrando em Produção Vegetal. Universidade Federal de Goiás, Escola de Agronomia, Avenida Esperança, s/n, Campus Samambaia, CEP: 74690-900, Goiânia, GO, Brasil. israelmmendes128@gmail.com

${ }^{3}$ Doutoranda em Fitotecnia. Universidade Federal de Uberlândia, Instituto de Ciências Agrárias - ICIAG, Avenida Amazonas, s/n, Bloco 2E, Sala 01, Bairro Umuarama, CEP: 38400-902, Uberlândia, MG, Brasil. joicyvmpeixoto@yahoo.com.br

${ }^{4}$ Professor Doutor em Solos. Universidade Federal de Uberlândia, Instituto de Ciências Agrárias - ICIAG, Avenida Amazonas, s/n, Bloco 2E, Sala 01, Bairro Umuarama, CEP: 38400-902, Uberlândia, MG, Brasil. elias@ufu.br

${ }^{5}$ Professor Doutor Fitopatologia. Instituto Federal de Educação, Ciência e Tecnologia Goiano - Campus Morrinhos, BR153, km 633, Zona Rural, CEP: 75.650-000, Morrinhos, GO, Brasil.rodrigo.silva@ifgoiano.edu.br
} 


\section{INTRODUÇÃO}

O quiabeiro Abelmoschus esculentus (L.) Moench é originário da África, especificamente na Etiópia. É uma planta da família malvaceae com grande adaptação em climas tropicais. No Brasil, a introdução desta olerácea ocorreu pelos escravos (Filgueira, 2008) sendo uma das hortaliças mais apreciadas pela população (Sediyama et al., 2009). Há uma estimativa de produção mundial de cerca de 1,7 milhões de ano $^{-1}$ (Asare-Bediako et al., 2014).

O sucesso do cultivo do quiabeiro depende da interação entre fatores edáficos, nutricionais, fitossanitários e fitotécnicos. Em relação à demanda nutricional, Galati et al. (2013) relatam que a sequência de acúmulo de nutrientes durante o ciclo do quiabeiro cv. Santa Cruz 47 é a seguinte: $\mathrm{K}>\mathrm{Ca}>\mathrm{N}>\mathrm{Mg}>$ $\mathrm{P}>\mathrm{S}>\mathrm{Fe}>\mathrm{B}>\mathrm{Mn}>\mathrm{Zn}>\mathrm{Cu}$. Assim, é primordial o fornecimento destes nutrientes em quantidade e qualidade para um crescimento e desenvolvimento satisfatório de plantas de quiabeiro.

Uma alternativa para a suplementação de cálcio e magnésio conjuntamente consiste no uso de silicatos. Além do potencial nutricional, os silicatos também atuam como corretivos do solo (Castro et al., 2011; Matos et al., 2014) e em função dos altos teores de cátions floculantes podem afetar a agregação do solo (Maio et al., 2011; Matos et al., 2014).

As propriedades físicas e químicas do solo sob a copa de plantas de cafeeiro podem apresentar condições propícias. Podem ocorrer aumentos dos teores de matéria orgânica e melhora na disponibilidade de nutrientes e agregação do solo (Santos et al., 2012). Ainda sob a copa, podem ocorrer menor adensamento do solo melhorando a disponibilidade de oxigênio (Guimarães et al., 2013). Ao contrário, propriedades físicas e químicas de solo sob pastagens estão mais proprensas à degradação. Normalmente há adensamento pelo trânsito de animais e consequentemente redução dos macroporos e redução da aeração (Resende et al., 2012).

Ressalta-se que atributos físicos do solo também são diretamente influenciados pelo manejo do solo praticado. Valarini et al. (2011) relatam que em hortas, o manejo do solo é baseado principalmente em revolvimento e ausência de cobertura do solo. Isso ocasiona a redução de teores de matéria orgânica e estabilidade de agregados. Desta forma, é preciso combinar estratégias de manejo eficiente para melhorar a qualidade nutricional e física do solo para o cultivo sustentável de hortaliças, tais como o quiabeiro.

O objetivo foi caracterizar os efeitos do silicato de cálcio e magnésio nas propriedades físicas e químicas de solos provenientes de pastagem, sob saia de cafeeiro e horta com cultivo de quiabo, além da produtividade do quiabeiro.

\section{MATERIALE MÉTODOS}

O estudo foi conduzido em Morrinhos, no Instituto Federal Goiano (1748'44.0"S 49¹2'14.4"W altitude 900 metros). O solo foi classificado como Latossolo Vermelho-Amarelo distrófico (Embrapa, 2013). Os principais atributos químicos, na profundidade de 0 20 cm, estão presentes na Tabela 1.

O clima da região, segundo Koppen, é tropical úmido, caracterizado por verão chuvoso e inverno seco. As precipitações e temperaturas ocorridas durante $o$ período experimental de julho de 2014 a junho de 2015 estão descritas na Figura 1.

Utilizou-se o delineamento em blocos ao acaso, com cinco tratamentos e cinco repetições. Os tratamentos consistiram em cinco doses de silicato de cálcio e magnésio: 0 ; 0,5; 1,0; 2,0 e 4,0 $\mathrm{tha}^{-1}$ e dois manejos alternativos adicionais (solo sob saia do cafeeiro por seis anos e solo sob pastagem por 10 anos). O silicato de cálcio e magnésio trata-se de um corretivo de solo e fertilizante mineral simples que possui 25\% de cálcio, $6 \%$ de magnésio e $10,5 \%$ de silício.

A aplicação de silicato ocorreu em canteiros (25 cm - profundidade; $1,30 \mathrm{~cm}$ de largura da base; 1,10 cm de largura de topo) estabelecidos por meio de enxada rotativa. A área possui histórico de horta a 18 anos. As distintas doses foram aplicadas em superfície com posterior incorporação via enxada rotativa. Cada canteiro foi considerado um bloco com $25 \mathrm{~m}$ de comprimento. Cada bloco foi composto por cinco parcelas de 5,0 $\mathrm{m}$ com os tratamentos. Os blocos se intercalaram a cada 1,5 metros. A coleta das amostras de solo sob a saia do cafezal e da pastagem foram realizadas em cinco repetições aleatoriamente.

Após 30 dias da aplicação do silicato realizouse o transplantio de mudas de quiabo (cultivar Santa Cruz 47). Foi realizado espaçamento duplo entre as plantas de $0,8 \mathrm{~m} \times 0,6 \mathrm{~m}$. As parcelas consistiram em 
Tabela 1 - Caracterização química do solo da área experimental antes da instalação do ensaio

\begin{tabular}{|c|c|c|c|c|c|c|c|c|c|c|}
\hline $\mathrm{pH}\left(\mathrm{H}_{2} \mathrm{O}\right)$ & $\mathrm{Ca}^{2+}$ & $\mathrm{Mg}^{2+}$ & $\mathrm{A}^{13+}$ & $\mathrm{P}$ & $\mathrm{K}^{+}$ & $\mathrm{H}+\mathrm{Al}$ & $\mathrm{T}$ & $\mathrm{V}$ & $\mathrm{m}$ & M.O. \\
\hline $1: 2,5$ & \multicolumn{3}{|c|}{$\mathrm{cmol}_{c} \mathrm{dm}^{-3}$} & \multicolumn{2}{|c|}{$\mathrm{mg} \mathrm{dm}^{-3}$} & \multicolumn{2}{|c|}{$\mathrm{cmol}_{c} \mathrm{dm}^{-3}$} & \multicolumn{2}{|c|}{$\%$} & $\mathrm{~g} \mathrm{~kg}^{-1}$ \\
\hline \multicolumn{11}{|c|}{ Horta } \\
\hline 5,9 & 2,7 & 0,9 & 0,0 & 42,3 & 212 & 4,2 & 8,34 & 50 & 0 & 4,9 \\
\hline \multicolumn{11}{|c|}{ Saia do cafeeiro (seis anos) } \\
\hline 5,8 & 2,6 & 0,6 & 0,0 & 36 & 195 & 4,3 & 7,99 & 46,24 & 0 & 4,3 \\
\hline \multicolumn{11}{|c|}{ Pastagem } \\
\hline 6,2 & 2,0 & 1,0 & 0,0 & 3,0 & 100 & 3,00 & 6,26 & 52 & 0 & 3,1 \\
\hline
\end{tabular}

pH em $\mathrm{H}_{2} \mathrm{O}$; $\mathrm{Ca}, \mathrm{Mg}, \mathrm{Al},\left(\mathrm{KCl} 1 \mathrm{~mol} \mathrm{~L}^{-1}\right) ; \mathrm{P}, \mathrm{K}=\left(\mathrm{HCl} \mathrm{0,05} \mathrm{mol} \mathrm{L}^{-1}+\mathrm{H}_{2} \mathrm{SO}_{4} 0,0125 \mathrm{~mol} \mathrm{~L}^{-1}\right)$ P disponível (extrator Mehlich $\left.{ }^{-1}\right)$; H + $\mathrm{Al}=($ Solução Tampão $-\mathrm{SMP}$ a pH 7,5); CTC a pH 7,0; V = Saturação por bases; $\mathrm{m}$ = Saturação por alumínio, M.O. = Método Colorimétrico. Metodologias baseadas em (Embrapa, 2011).

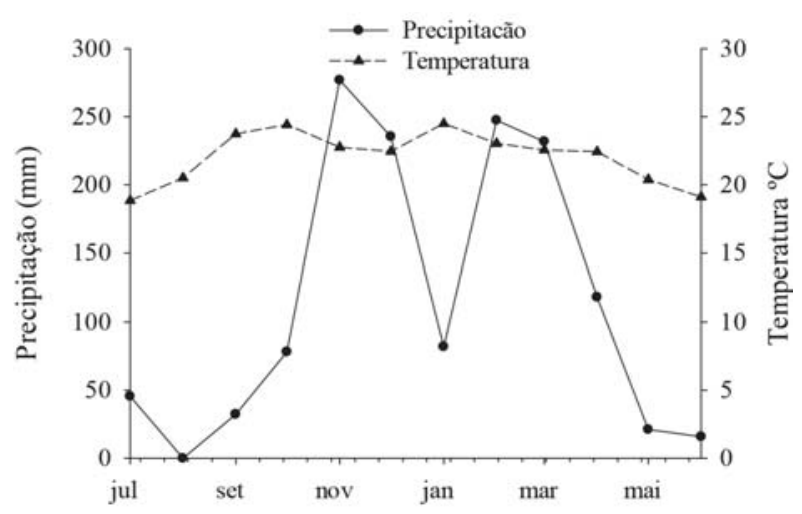

Figura 1 - Médias de precipitação e temperatura da área experimental de julho de 2014 a junho de 2015.

12 plantas centrais mais duas plantas nas extremidades por tratamento.

No cultivo de quiabo empregou-se adubação de plantio e cobertura de acordo com a análise de solo inicial (Correia et al., 1999). Utilizou-se no plantio 400 $\mathrm{kg} \mathrm{ha}^{-1}$ do formulado 08-28-18 (20 cova-1 $^{-1}$ e em cobertura aos 20,50 e 80 dias após o transplantio, $200 \mathrm{~kg} \mathrm{ha}^{-}$ ${ }^{1}$ do formulado 20-00-20 (10 g cova $\left.^{-1}\right)$.

O manejo de plantas daninhas ocorreu por meio de capina. Não se registrou insetos e patógenos ocasionando danos econômicos a cultura do quiabo, com exceção de formigas cortadeiras na fase de póstransplantio das mudas que foram controladas por meio de iscas. A colheita de quiabo foi realizada a partir dos 60 dias após o transplantio, duas vezes por semana durante 75 dias, para determinação da produtividade.

As áreas de pastagem e a cafezal são vizinhas dos canteiros de quiabo. O cafezal encontra-se ao lado da área experimental do quiabo. A pastagem encontrase a $30 \mathrm{~m}$ do quiabo. A pastagem já está na área a 10 anos e o cafezal a seis anos. A pastagem era realizada de acordo com a altura da Urochloa ruziziensis mantendose altura de pastejo entre 15 a 40 cm. No cafezal há transito de trator com roçadeira nas entrelinhas para evitar o crescimento de ervas daninhas. Para estes dois tratamentos juntamente com os referentes a doses de silicato sob cultivo de quiabo estimou-se as seguintes características físicas do solo: argila dispersa em água, grau de floculação, macroporosidade, microporosidade, porosidade total e diâmetro médio geométrico.

A coleta das amostras deformadas e indeformadas foram realizadas na profundidade de 5,0 a $10,0 \mathrm{~cm}$, em duplicata por repetição. A amostragem foi manual com uso de um enxadão e uma pá-reta, abrindo-se trincheiras com dimensões de aproximadamente 10 $\mathrm{x} 20 \times 25 \mathrm{~cm}$.

As amostras deformadas foram usadas para determinação de: argila dispersa em água (ADA), grau de floculação (GF), diâmetro médio geométrico (DMG) e textura. As amostras indeformadas foram coletadas utilizando-se anéis volumétricos com auxílio de amostrador tipo Uhland para determinação da densidade do solo (Ds), macroporosidade (Ma), microporosidade (Mi) e porosidade total (Pt).

A determinação da argila dispersa em água (ADA) foi realizada via método da pipeta volumétrica, conforme (Embrapa, 2011). Com base nos teores de argila total e argila dispersa em água, determinou-se o grau de floculação da fração argila (GF), por meio da seguinte equação:

$$
\mathrm{GF}=((\mathrm{a}-\mathrm{b}) / \mathrm{a}) * 100
$$


Sendo:

GF = grau de floculação, em \%;

$\mathrm{a}=$ argila total, em $\mathrm{g} \mathrm{kg}^{-1}$;

$\mathrm{b}=$ argila dispersa em água, em $\mathrm{g} \mathrm{kg}^{-1}$.

A estabilidade dos agregados em água foi avaliada pelo método do peneiramento úmido. Para isso, agregados de tamanho 2-4 mm foram agitados por 4 min. no aparelho de Yoder (Yoder, 1936) em conjunto de peneiras de abertura de 2; 1; 0,5 e 0,25 mm. Conhecendose a massa de agregados presente em cada peneira após o ensaio, determinou-se o diâmetro médio geométrico (DMG) por meio da seguinte expressão:

$$
\mathrm{DMG}=\Sigma \mathrm{n} \cdot \log \mathrm{d}
$$

Sendo:

DMG = diâmetro médio geométrico $(\mathrm{mm})$;

$\mathrm{n}$ = percentagem de agregados em cada classe de tamanho de agregados, expressa em decimal;

d = diâmetro médio de cada classe de tamanho de agregados (mm).

Inicialmente, a análise estatística foi conduzida por meio de verificação de pressupostos de análise de variância (Teste de Shapiro-Wilk - Normalidade). $\mathrm{Na}$ ausência de normalidade, os dados foram transformados (Box-Cox e Remove Trend).

A análise de variância foi conduzida de duas formas. Quando se consideraram somente os tratamentos quantitativos referentes a doses de silicatos empregouse regressão na análise de variância. A comparação das distintas doses de silicato com a saia do cafeeiro e pastagem empregou-se análise de variância sendo as médias comparadas por meio do Teste de Dunnet.

\section{RESULTADOS E DISCUSSÃO}

Os efeitos positivos do silicato de cálcio e magnésio podem ocorrer devido ao aumento do $\mathrm{pH}$ do solo e dos teores de silício disponível (Figura 2) proporcionando maior crescimento radicular. Além disso, fornecem cálcio e magnésio. Neste estudo o silicato de cálcio e magnésio não contribuiu com o aumento da produtividade de plantas de quiabo comparado à sua ausência. Em plantas acumuladoras a inclusão do silicato altera a arquitetura da planta favorecendo a captação de luz e $\mathrm{CO}_{2}$ e reduzindo a transpiração pela maior rigidez na parede
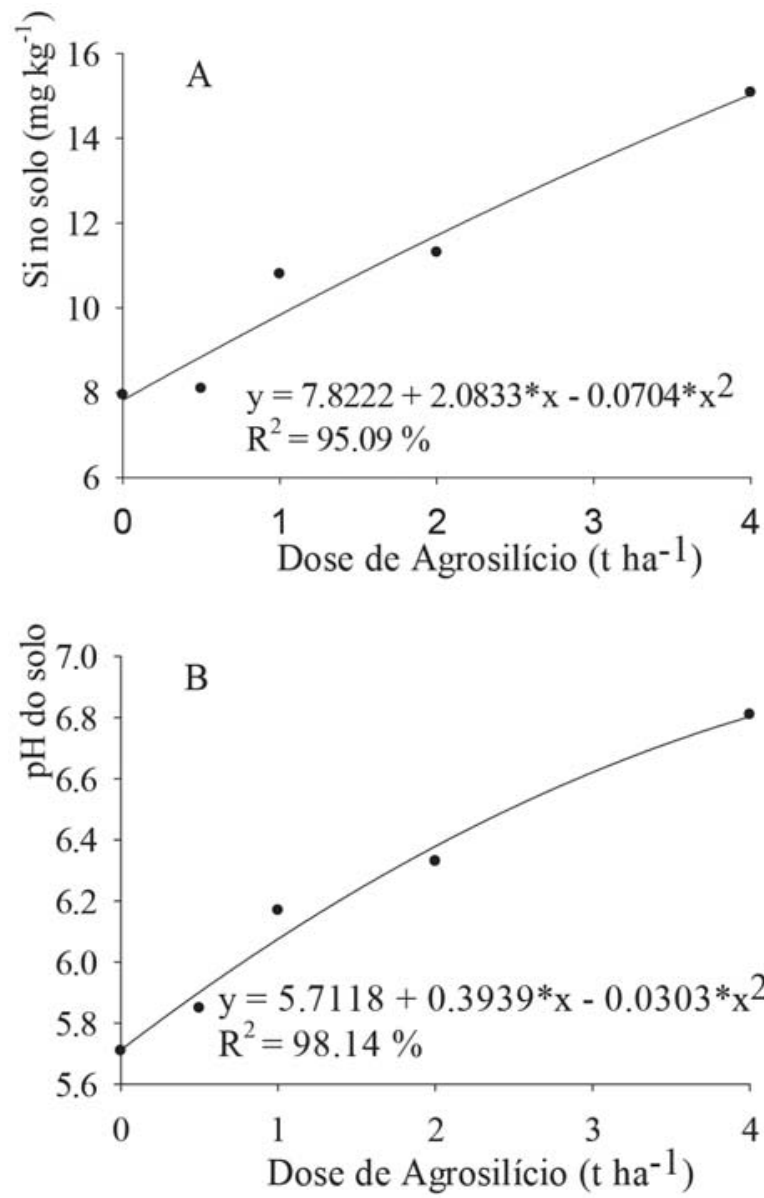

Figura 2 - Teores de Si no solo (A) e concentração do $\mathrm{pH}$ (B) e em função de doses de silicato de cálcio e magnésio.

celular (Guntzer et al., 2012). Portanto, tais condições potencializam a fotossíntese e a eficiência do uso da água e nutrientes culminando em maior produtividade. Resultados semelhantes também são descritos por: Dantas Júnior et al. (2013), para a cultura do milho; Barbosa et al. (2008), para a cultura do sorgo; Sarto et al. (2015), para a cultura do trigo e Castro \& Crusciol (2015), para rotações envolvendo soja, trigo, milho e feijão. Em culturas de cevada e algodão (família malvaceae) Rodrigues et al. (2011), na presença de Si e em condições de estresse salino, encontraram a presença de enzimas que garantiram a preservação da parede celular.

O aumento do $\mathrm{pH}$ do solo provocado pelo silicato de cálcio e magnésio provoca efeito de correção de 
acidez do solo. Os íons $\mathrm{SiO}_{3}$ reagem com íons $\mathrm{H}^{+}$ ocasionando respostas de neutralização ou alcalinidade. Sarto et al. (2015) relatam que a aplicação de silicato de cálcio e magnésio proporciona uma redução da acidez potencial e do teor de alumínio bem como um aumento do $\mathrm{pH}$ do solo, disponibilidade de cálcio, magnésio e silício, e por fim aumento da CTC (capacidade de troca de cátions). Além disso, Castro \& Crusciol (2015) também descrevem os efeitos positivos de silicatos na disponibilização de fósforo.

Sarto et al. (2015) relatam que os efeitos positivos dos silicatos só ocorrem em solos com $\mathrm{pH}$ inferior a 5,3. Conforme a Tabela $1, \mathrm{opH}$ da área antes da aplicação de silicato era de 5,9. Desta forma, é importante frisar que os efeitos do silicato dependem da forma e de um tempo após a aplicação para a reação dos íons no solo.

Resende et al. (2012) relatam que o manejo do solo pode alterar os atributos físicos e conseqüentemente a sustentabilidade no uso do solo. Desta forma, acompanhar a evolução das características físicas do solo é fundamental para avaliar a qualidade do solo e de seu manejo.

Os atributos físicos do solo referentes a: macroporo, microporo, porosidade total e densidade do solo não foram afetados pelos manejos praticados na horta (com adubação silicatada de cálcio e magnésio), no cafezal e na pastagem (Tabela 2). Desta forma, a distribuição granulométrica entre as diferentes áreas foi considerada semelhante.

A situação do solo sob pastagem não alterou a densidade do solo. A densidade do solo é medida indireta para se estimar o nível de compactação do solo (Spera et al., 2009). Em situações de pastejo espera-se uma

Tabela 2 - Valores de F referentes a significância do efeito de doses do silicato de cálcio e magnésio e manejos de solo (café, pastagem)

\begin{tabular}{|c|c|}
\hline Atributos físicos & Teste F \\
\hline Macroporo $\left(\mathrm{cm}^{3} \mathrm{~cm}^{-3}\right)$ & $1,83^{\mathrm{ns}}$ \\
\hline Microporo $\left(\mathrm{cm}^{3} \mathrm{~cm}^{-3}\right)$ & 2,24 ns \\
\hline Porosidade total $\left(\mathrm{cm}^{3} \mathrm{~cm}^{-3}\right)$ & $2,07 \mathrm{~ns}$ \\
\hline Densidade do solo $\left(\mathrm{g} \mathrm{cm}^{-3}\right)$ & $1,86^{\mathrm{ns}}$ \\
\hline Argila dispersa em água ( $\left.\mathrm{g} \mathrm{Kg}^{-1}\right)$ & $21,37 * *$ \\
\hline Grau de Floculação (\%) & $13,67 * *$ \\
\hline Diâmetro médio dos agregados $(\mathrm{mm})$ & $3,02 *$ \\
\hline
\end{tabular}

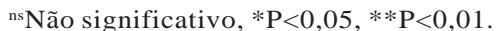

tendência de aumento de densidade em função de pisoteio dos animais. Resultados semelhantes são descritos por Mantovanelli et al. (2015) que avaliaram o efeito de distintos manejos em solos amazônicos e não observaram alterações na densidade decorrente do pisoteio dos animais.

O manejo do solo provocou alterações nos seguintes atributos: argila dispersa em água, grau de floculação e diâmetro médio geométrico (Tabelas 2 e 3). Desta forma, a agregação do solo foi afetada por práticas de manejo variável.

Verifica-se que o solo sob pastagem por dez anos apresentou o maior teor de argila dispersa em água e um dos menores graus de floculação (Tabela 3). Embora não tenha havido diferenças em relação a densidade do solo, os maiores teores de argila dispersa e o baixo grau de floculação são indicativos de formação de camada compactadas e deteriorização das propriedades físicas do solo.

A menor estabilidade de agregados, medida por meio do diâmetro médio dos agregados, foi observada na área de horta sem adubação de silicato de cálcio e magnésio (Tabela 3). A ausência de cátions $\mathrm{Ca}^{2+} \mathrm{e}$ $\mathrm{Mg}^{2+}$ por não utilizar a fonte silicatada são as principais responsáveis por diminuir a estabilidade de agregados. Matos et al. (2014) comentam os efeitos de cátions cálcio e magnésio, na agregação do solo decorrem da: disponibilização de cálcio que atua na formação de complexos argila-humus; estímulo a atividade microbiana com subseqüente decomposição de matéria orgânica e liberação de compostos ligantes entre as partículas do solo. Santos et al. (2012) também relaciona as maiores taxas de matéria orgânica no solo com o aumento da agregação do solo.

O solo sob saia de cafeeiro, quando comparado aos demais tratamentos, apresentou menor argila dispersa em água e consequentemente maior valor do grau de floculação, denotando maior agregação do solo. Já o solo sob pastagem durante 10 anos apresentou maior ADA e menor GF, demonstrado menor agregação do solo. Provavelmente a menor quantidade de ADA em cafeeiro está associada á formação e estabilidade dos agregados pela maior quantidade de matéria orgânica existente abaixo das plantas de café devido a folhas que caem no solo. Aliado a isso se tem o não revolvimento do solo, menor compactação quando comparado a solo sob pastagem, além de maior número de microrganismos. 
Esses fatores contribuem para a agregação do solo. A matéria orgânica contribui para a agregação do solo (Prado et al., 2014). Lima et al. (2013) ao estudarem vegetação natural e pastagem, observaram menor argila dispersa em água e maior grau de floculação e consequentemente maior agregação do solo no primeiro ambiente. Esse trabalho corrobora aos resultados observados no presente estudo.

O silicato de Ca e Mg não afeta a quantidade de macroporos, microporos, porosidade total e a densidade do solo. O mesmo é observado nos solos sob saia do cafeeiro e pastagem de dez anos (Tabela 4). Provavelmente não foi observado diferença entre essas características devido ao curto período de duração do estudo e também a inexistência de salinização em solos do cerrado. O aumento de Ca na solução do solo reduz a sua salinidade
$\left(\mathrm{Cl}^{-}\right.$e $\left.\mathrm{Na}^{+}\right)$, consequentemente melhorando a sua estrutura (Moreira \& Kassuya, 2016).

Obalum \& Obi (2016) avaliando dois sistemas de cultivo, o convencional e o plantio direto, não observaram diferença na quantidade de macroporos e de microporos no solo. Nogueira et al. (2016) estudando o efeito residual de calcário e gesso agrícola em sistema de manejo convencional e direto não observaram diferença na densidade do solo. Essas propriedades físicas do solo sofrem alterações a longo prazo conferindo maior resistência a condições impostas. No experimento conduzido por Castro et al. (2011), a microporosidade, macroporosidade, porosidade total e densidade do solo não foram afetados pela aplicação de calcário e silicato e nem pelos sistemas de rotação de cultura. Nesse trabalho a quantidade de macroporos

Tabela 3 - Argila dispersa em água (ADA), grau de floculação (GF), diâmetro médio dos agregados de solos sob diferentes manejos (horta, cafezal e pastagem) e produtividade do quiabeiro sob doses de silicato de cálcio e magnésio

\begin{tabular}{|c|c|c|c|c|}
\hline Tratamentos & $\operatorname{ADA}\left(\mathrm{g} \mathrm{Kg}^{-1}\right)$ & GF(\%) & $\mathrm{DMG}(\mathrm{mm})$ & Prod. Quiabeiro(t ha-1) \\
\hline Silicato $\left(0,0 \mathrm{t} \mathrm{ha}^{-1}\right)$ & $15,26 *$, $\%$ & $96,24 *,{ }^{a} \%$ & $0,73 *,{ }^{\mathrm{a}} \%$ & 11,24 \\
\hline Silicato $\left(0,5 \mathrm{t} \mathrm{ha}^{-1}\right)$ & 6,63 а\% & 98,53 а\% & $1,03 \mathrm{~ns}$ & 11,59 \\
\hline Silicato $\left(1,0 \mathrm{t} \mathrm{ha}^{-1}\right)$ & 10,48 a\% & 97,08 а\% & $0,88^{\mathrm{ns}}$ & 10,47 \\
\hline Silicato $\left(2,0 \mathrm{t} \mathrm{ha}^{-1}\right)$ & $12,91 *$, $\%$ & $96,39 *$, a $\%$ & 1,04 ns & 12,57 \\
\hline Silicato $\left(4,0 \mathrm{t} \mathrm{ha}^{-1}\right)$ & 10,90 а\% & 97,32 а\% & $0,95 \mathrm{~ns}$ & 13,26 \\
\hline Solo sob saia de cafeeiro & 5,69 a\% & 98,58 а\% & 1,09 ns & - \\
\hline Solo sob pastagem de dez anos & $26,54 *$ & $93,30 *$ & 1,10 ns & - \\
\hline DMS & 5,89 & 1,88 & 0,29 & - \\
\hline CV (\%) & 26,73 & 1,12 & 17,34 & 28,12 \\
\hline
\end{tabular}

*Médias, na coluna, diferente do solo sob saia de cafeeiro pelo teste de Dunnett $(\mathrm{P}<0,05)$.

a\%Médias, na coluna, diferente do solo sob pastagem, pelo teste de Dunnett $(\mathrm{P}<0,05)$.

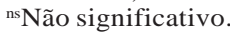

Tabela 4 - Macroporos, Microporos, Porosidade total e Densidade do solo sob diferentes manejos (horta, cafezal e pastagem sob doses de silicato de cálcio e magnésio

\begin{tabular}{|c|c|c|c|c|}
\hline Tratamentos & Macroporo & Microporo & Porosidade total & Densidade do solo \\
\hline & & $\mathrm{cm}^{3} \mathrm{~cm}^{-3}$ & & $\mathrm{~g} \mathrm{~cm}^{-3}$ \\
\hline Silicato $\left(0,0 \mathrm{t} \mathrm{ha}^{-1}\right)$ & 0,2255 ns & 0,1984 ns & 0,4240 ns & 1,69 ns \\
\hline Silicato $\left(0,5 \mathrm{t} \mathrm{ha}^{-1}\right)$ & 0,2267 ns & 0,2049 ns & 0,4316 ns & $1,73 \mathrm{~ns}$ \\
\hline Silicato $\left(1,0 \mathrm{t} \mathrm{ha}^{-1}\right)$ & 0,2209 ns & $0,1931 \mathrm{~ns}$ & $0,4141^{\mathrm{ns}}$ & $1,64 \mathrm{~ns}$ \\
\hline Silicato $\left(2,0 \mathrm{t} \mathrm{ha}^{-1}\right)$ & 0,2231 ns & $0,1978^{\mathrm{ns}}$ & 0,4209 ns & $1,68 \mathrm{~ns}$ \\
\hline Silicato $\left(4,0 \mathrm{t} \mathrm{ha}^{-1}\right)$ & 0,2224 ns & 0,1953 ns & $0,4177^{\mathrm{ns}}$ & $1,66^{\mathrm{ns}}$ \\
\hline Solo sob saia de cafeeiro & 0,2212 ns & $0,1993 \mathrm{~ns}$ & $0,4205^{\mathrm{ns}}$ & $1,67 \mathrm{~ns}$ \\
\hline Solo sob pastagem de dez anos & 0,2286 ns & $0,2123^{\mathrm{ns}}$ & 0,4409 ns & $1,78^{\mathrm{ns}}$ \\
\hline DMS & 0,0084 & 0,0168 & 0,0247 & 0,13 \\
\hline $\mathrm{CV}(\%)$ & 2,16 & 4,83 & 3,35 & 4,45 \\
\hline
\end{tabular}

*Médias diferentes do solo sob saia de cafeeiro, na coluna por Dunnett $(\mathrm{P}<0,05)$.

a\%Médias diferentes do solo sob pastagem, na coluna por Dunnett $(\mathrm{P}<0,05)$.

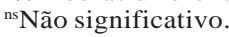


aumentou com a aplicação dos corretivos, entretanto, o valor quantificado ficou abaixo do valor mínimo de $10 \%$, caracterizado como limite crítico para a aeração do solo não se torne limitada (Lier, 2010). Esses trabalhos vão de encontro aos resultados obtidos no presente estudo.

\section{CONCLUSÕES}

O silicato de cálcio e magnésio não aumenta a produtividade de plantas de quiabo em solo com $\mathrm{pH}$ acima de 5,9.

O silicato de Ca e Mg melhoram os atributos físicos associados a agregação do solo (diâmetro médio agregado, grau de floculação e argila dispersa em água).

O silicato de cálcio e magnésio reduz a acidez do solo e eleva os teores de cálcio, magnésio e silício disponíveis no solo.

\section{AGRADECIMENTOS}

A AGRONELLI pelo fornecimento do silicato de cálcio e magnésio. Ao IFGoiano Campus Morrinhos por disponibilidade de desenvolvimento da pesquisa.

\section{REFERÊNCIAS BIBLIOGRÁFICAS}

ALMEIDA, R.F.; MACHADO, H.A.; MARTINS, F.P. et al. Correlação do tamanho e distribuição dos agregados em latossolos amarelo da região do triângulo mineiro em diferentes ambientes. Bioscience Journal, v.30, n.5, p.1325-1334, 2014. http://www.seer.ufu.br/index.php/ biosciencejournal/article/view/22146

ASARE-BEDIAKO, E.; ADDO-QUAYE, A.A.; BIKUSI, A. Comparative efficacy of phytopesticides in the management of Podagrica spp and mosaic disease on okra (Abelmoschus esculentus L.).

American Journal of Experimental Agriculture, v.4, n.8, p.879-889, 2014. http:// www.sciencedomain.org/abstract/4054

BARBOSA, N.C.; VENÂNCIO, R.; ASSIS, M.H.S. et al. Formas de aplicação de silicato de cálcio e magnésio na cultura do sorgo em neossolo quartzarênico de Cerrado. Pesquisa

Agropecuária Tropical, v.38, n.4, p.290-296, 2008. https://www.revistas.ufg.br/pat/article/view/ 3861
CASTRO, G.S.A.; CALONEGO, J.C.; CRUSCIOL, C.A.C. Propriedades físicas do solo em sistemas de rotação de culturas conforme o uso de corretivos da acidez. Pesquisa Agropecuária Brasileira, v.46, n.12, p.1690-1698, 2011. https://seer.sct.embrapa.br/ index.php/pab/article/view/10362

CASTRO, G.S.A.; CRUSCIOL, C.A.C. Effects of surface application of dolomitic limestone and calcium-magnesium silicate on soybean and maize in rotation with green manure in a tropical region. Bragantia, v.74, n.3, p.311-321, 2015. http:// dx.doi.org/10.1590/1678-4499.0346

CATES, A.M.; RUARK, M.D.; HEDTCKE, J.L. et al. Long-term tillage, rotation and perennialization effects on particulate and aggregate soil organic matter. Soil and Tillage Research, v.155, p.371-380, 2016. http://www.sciencedirect.com/ science/article/pii/S0167198715300258

CORREIA, L.G.; AVELAR FILHO, J.A.; NAGAI, H. Quiabo. In: RIBEIRO, A.C.; GUIMARÃES, P.T.G.; ALVAREZ, V.V.H. (Ed.). Recomendações para o uso de corretivos e fertilizantes em Minas Gerais. Viçosa: Comissão de fertilidade. 1999, p.25-32.

DANTAS JÚNIOR, E.E.; CHAVES, L.H.G.; COSTA, F.A.M. et al. Silicate fertilizer and irrigation depth in corn production. Revista Ceres, v.60, n.4, p.563-568, 2013. http://dx.doi.org/10.1590/S0034737X2013000400016

\section{EMBRAPA. EMPRESA BRASILEIRA DE} PESQUISA AGROPECUÁRIA. Manual de métodos de análises de solo. $2^{\text {a }}$. ed. Rio de Janeiro: Embrapa Solos, 2011, 230p.

EMBRAPA. EMPRESA BRASILEIRA DE PESQUISA AGROPECUÁRIA. Sistema Brasileiro de Classificação de Solos. $3^{\text {a }}$. ed. Rio de Janeiro: Embrapa Solos, 2013. 350p.

FILGUEIRA, F.A.R. Novo manual de olericultura: agrotecnologia moderna na produção e na comercialização de hortaliças. Viçosa: UFV, 2008. 421p.

GALATI, V.C.; FILHO, A.B.C.; GALATI, V.C. et al. Growth and accumulation of nutrients of the okra crops. Semina: Ciências Agrárias, v.34, n.1, p.191-200, 2013. http://www.uel.br/revistas/uel/ index.php/semagrarias/article/view/9622 
GUIMARÃES, G.P.; MENDONÇA, E.S.; PASSOS, R.R. et al. Avaliação da qualidade do solo e de cafeeiros em propriedade familiar do Território do Caparaó-ES. Revista Brasileira de

Agroecologia, v.8, n.3, p.236-246, 2013. http:// www.aba-agroecologia.org.br/revistas/index.php/ rbagroecologia/article/view/13347

GUNTZER, F.; KELLER, C.; MEUNIER, J.D.

Benefits of plant silicon for crops: a review.

Agronomy for Sustainable

Development, v.32, n.1, p.201-213, 2012. https://

link.springer.com/article/10.1007/s13593-011-0039-8

LIER, Q.J.V. Física do Solo. Viçosa:

Sociedade Brasileira de Ciência do Solo, 2010. 298p.

LIMA, J.S.S.; SOUZA, G.S.; SILVA, S.A.

Distribuição espacial da matéria orgânica, grau de floculação e argila dispersa em água em área de vegetação natural em regeneração e pastagem. Revista Árvore, v.37, n.3, p.539-546, 2013. http://dx.doi.org/10.1590/S0100-

67622013000300017

MAIO, M.M.; SAMPAIO, R.A.; NASCIMENTO, A.L. et al. Atributos físicos do solo, adubado com lodo de esgoto e silicato de cálcio e magnésio. Revista Ceres, v.58, n.6, p.823-830, 2011. http://dx.doi.org/10.1590/S0034-

737X2011000600021

MATOS, A.T.; ALMEIDA NETO, O.B.; MATOS, M.P. Saturação do complexo de troca de solos oxídicos com sódio. Revista Brasileira de Engenharia Agrícola e Ambiental, v.18, n.5, p.501-506, 2014. http://dx.doi.org/10.1590/ S1415-43662014000500006

MOREIRA, F.M.S.; KASUYA, C.M. Fertilidade e biologia do solo: integração e tecnologia para todos. Viçosa: Sociedade Brasileira de Ciência do Solo, 2016, 592p.

NOGUEIRA, K.B.; ROQUE, C.G.; BORGES, M.C.R.Z. et al. Atributos físicos do solo e matéria orgânica sob dois manejos e efeito residual da aplicação de calcário e gesso agrícola. Revista de la Facultad de Agronomía, v.115, n.1, p.45-54, 2016. http://www.agro.unlp.edu.ar/revista/ index.php/revagro/article/view/284
OBALUM, S.E.; OBI, M.E. Physical properties of a sandy loam Ultisol as affected by tillage-mulch management practices and cropping systems.

Soil \& Tilage Research, v.108, n.1-2, p.3036, 2010. http://doi.org/10.1016/j.still.2010.03.009

PRADO, E.A.F.; VITORIO, A.C.T.; OLIVEIRA, W.H. et al. Índice de dispersão de agregados de um Latossolo Vermelho distroférrico cultivado com cana sob aplicação de vinhaça. Seminha: Ciências Agrária, v.35, n.4, p.2347-2356, 2014. http://www.redalyc.org/ articulo.oa?id=445744143009

RESENDE, T.M.; MORAES, E.R.; FRANCO, F.O. et al. Avaliação física do solo em áreas sob diferentes usos com adição de dejetos animais no bioma cerrado. Bioscience Journal, v.28, n.1, p.179-184, 2012. http://www.seer.ufu.br/index.php/ biosciencejournal/article/view/13320

RODRIGUES, F.A; OLIVEIRA, L.A.; KORNDORFER, A.P. et al. Silício: um elemento benéfico e importante para as plantas. IPNI. Informações agronômicas, n.134, 2011.

SANTOS, D.S.; ARRUDA, E.M.; MORAES, E.R. et al. Atributos físicos e matéria orgânica de áreas de latossolo utilizadas para atividade pecuária no bioma cerrado. Bioscience Journal, v.28, n.4, p.500-508, 2012. http://www.seer.ufu.br/index.php/ biosciencejournal/article/view/13287

SARTO, M.V.M.; LANA, M.C.; RAMPIM, L. et al. Effects of silicate application on soil fertility and wheat yield. Semina: Ciências Agrárias, v.36, n.6 (Suplemento 2), p.4071-4082, 2015. http:// www.uel.br/revistas/uel/index.php/semagrarias/ article/view/18977

SEDIYAMA, M.A.N.; SANTOS, M.R.; VIDIGAL, S.M. et al. Produtividade e estado nutricional do quiabeiro em função da densidade populacional e do biofertilizante suíno. Bragantia, v.68, n.4, p.913-920, 2009. http://dx.doi.org/10.1590/S000687052009000400011

SPERA, S.T.; SANTOS, H.P.; TOMM, G.O. et al. Effect of crop-livestock under no-tillage on some soil physical attributes after ten years.

Bragantia, v.69, n.4, p.695-704, 2010. http:// dx.doi.org/10.1590/S0006-87052010000300022 
VALARINI, P.J.; OLIVEIRA, F.R.A.;

SCHILICKMANN, S.F. et al. Qualidade do solo em sistemas de produção de hortaliças orgânico e convencional. Horticultura Brasileira, v.29, n.4, p.485-491, 2011. http://www.scielo.br/pdf/hb/ v29n4/a07v29n4.pdf
YODER, R.E. A direct method of aggregate analysis of soil and a study of the physical nature of erosion losses. Journal of

America Society of Agronomy, v.28, n.5, p.337-357, 1936. https://dl.sciencesocieties.org/ publications/aj/abstracts/28/5/

AJ0280050337?access $=0 \&$ view $=$ pdf

Recebido para publicação em 13/4/2017 e aprovado em 22/10/2017. 